\title{
Simulation of Poly (ADP-ribose) polymerase (PARP) Enzyme with BAI Compound in the for Thyroid Cells
}

\author{
Hasan Tuhmaz Hamd \\ Thi-Qar University, College of Medicine, Nasiriyah, Thi-Qar, Iraq
}

\begin{abstract}
In this study, the simulation for the preparation of pharmacological compound anti-cancer Baicalein (6,7-dihydroxy-2-phenyl-4H-chromen-4-one). These compounds have an importance of the known biologic and its wide medical requests. Our theoretical results dedicated to simulating that acquired for researchers (SE EUN HAN et. al) Practically against cancerous cells in the thyroid gland and matching them through a program (MOE) theoretically. From the illustrious effects, the compound (BAI) is behaving as a good legend when it interacted with amino acid for the enzyme (PARP).
\end{abstract}

Key words: Docking, BAI, anticancer, FOR Thyroid cells

\section{Introduction}

Flavonoids contain of a large set of polyphenolic compounds consuming a benzo- $\gamma$-pyrone configuration and areubiquitouslycurrentin plants. Theyare synthesized by phenylpropanoid alleyway. Obtainable reports be likely to show that subordinate metabolites of phenolic environment counting flavonoids are responsible for the variety of pharmacological activities [1, 2]. Flavonoids are hydroxylated phenolic substances and are known to be combined by plants in reaction to microbial infection [3]. Their activities are structure reliant on. The chemical nature of flavonoids be contingent on their structural course, degree of hydroxylation, other substitutions and conjugations, and degree of polymerization [4]. Topical interest in these substances has been motivated by the thinkable health assistances rising from the antioxidant actions of these polyphenolic compounds. Purposeful hydroxyl groups in flavonoids arbitrate their antioxidant effects by scavenging free radicals by chelating metal ions $[5,6]$. The chelation of metals be able to vital in the avoidance of radical generation which damage impartial bio-molecules [7, 8]. As a dietary component, flavonoids are supposed to have health-stimulating properties due to their great antioxidant capacity both in vivo and in vitro systems [9, 10]. Flavonoids have capability to induce human protective enzyme organisms. The number of trainings has suggested protective effects of flavonoids in contradiction of frequent infectious (bacterial and biological diseases) and degenerative infections such as cardiovascular diseases, cancers, and further age-amalgamated diseases [2, 9, 10]. The mechanisms tangled in safety providing by flavonoids are termed separately. Flavonoids also performance as a secondary antioxidant defense system in plant tissues showing to different abiotic and biotic stresses. Flavonoids are situated in the nucleus of mesophyll cells and within centers of ROS generation. They also regulate growth factors in plants such as auxin [11]. Bio-synthetic genes have been accumulated in several bacteria and mushrooms for improved creation of flavonoids [12] Flavonoids are a set of natural compounds with variable phenolic assemblies and are established in plants. In 1930 a novel substance was quarantined from oranges. At that time, it was supposed to be a member of a new class of vitamins and was selected as vitamin $P$. Advanced on it converted clear that this substance was a flavonoid (ruin) and till now more than 4000 varieties of flavonoids have been identified [13]. The poly (ADPribose) polymerases (PARPs) are an emerging family of enzymes that share the ability to catalyze the transfer of ADP-ribose to target proteins (poly ADP-ribosylation) $[14,15]$. There are at least 18 members of the PARP family that are encoded by different genes, and stake homology in a preserved catalytic domain.1 Although some isoforms containing PARP1 and PARP2 are finest known for their involvement in DNA reparation routes, it is now clear that these and other PARPs have an important role in several cellular processes including cell proliferation and cell death. A number of cellular 
substrates for PARP have been well-defined, and a mainstream of these proteins are nuclear proteins that are complicated in nucleic acid metabolism, modulation of chromatin structure, DNA synthesis, and DNA restoration. PARP also auto transforms itself in the appearance of DNA filament breakdowns, and is one of the chief acceptors of poly ADP ribose in vivo. PARP1 is the first and best described member of the PARP family. PARP2 is supreme cautiously related to PARP1 with $69 \%$ match in its catalytic domain, and was predictable on the foundation of the perseverance of PARP activity in PARP1deficient cells $[14,16]$. Thyroid tumors are present broadly classified as follicle-derived (thyroid epithelial) neoplasms, other epithelial tumors, non-epithelial tumors and secondary tumors assembled on pathological, clinical and genetic characteristics $[17,18]$. These tumors can be benevolent, borderline or malignant, focus on their biological performance within the body. The follicular adenoma, hyalinizing trabecular tumor, encapsulated follicular-patterned thyroid tumors, papillary thyroid carcinoma (PTC), follicular thyroid carcinoma, Hürthle cell tumour, poorly differentiated thyroid carcinoma, anaplastic thyroid carcinoma and squamous cell carcinoma comprise the major thyroid epithelial neoplasms. Some of the other epithelial tumors found in the thyroid gland have medullary carcinoma, salivary gland-type tumors, mucinous carcinoma and thymic tumors, at the same time as tumors like paraganglioma, peripheral nerve sheath, vascular, smooth muscle, solitary fibrous and histiocytic tumors, lymphoma and teratoma fall under the non-epithelial tumors of the thyroid [16-19]. The well separated thyroid cancer such as follicular and papillary carcinomas description for $95 \%$ of all thyroid cancer cases and are regularly interrelated with a good prognosis and existence rate when detected early [19]. On the other hand, the injured or undistinguishable anaplastic thyroid carcinoma, albeit a rare cancer, is nearly continually fatal [18].

\section{Materials and Method}

These compound are generally used in pharmaceuticals and their effectiveness has been measured against cancer by advanced programs (MOE).

A-MOE program 2015.

Docking study Ligand: In the field of molecular forming, docking is a method which expects the preferred orientation of one molecule to a second when bound to each other to form a stable complex. Molecular Network software packages provide Chem 3D, which was used for the generation of 3D coordinates from. Again, using Converter of these same server 2D structures of the drugs was converted into PDB format which is an acceptable form for any standard docking software. Finally using MOE were prepared by the addition of hydrogen atoms. Structures.

B-(BAI) Baicalein (6,7-dihydroxy-2-phenyl-4Hchromen-4-one).<smiles>O=c1cc(-c2ccccc2)oc2cc(O)c(O)cc12</smiles>

C- 4-(4-carbamoyl-1-methyl-3-oxoisoindolin-2yl)-1-C-cyclohexylpiperidi1-ium.

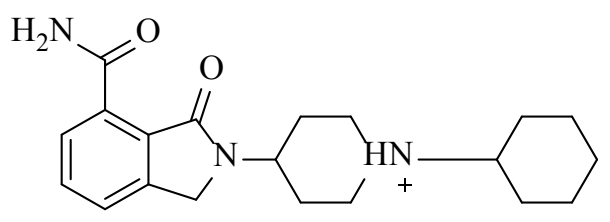

D- PARP poly (ADP-ribose) polymerases.

\section{Results and Discussion}

Docking Analysis, the docking scores were obtained from (Baicalein (6,7-dihydroxy-2-phenyl-4H-chromen4-one) withe against (PARP) receptor. The output of all ligands was given by energy values in $\mathrm{kcal} / \mathrm{mol}$ as shown in Table 1. Some ligands show good docking scores when compared to standard drug. Docking score of the compounds targeted was compared with the score of the drug Baicalein (6,7-dihydroxy-2-phenyl-4H-chromen4-one) which is used as a potent drug for the treatment of tumor show higher docking scores in comparison with standard drug. The interactions were stronger for all the ligands which are used for docking simulation table (13) Validation of Ligands. The results showed in Tables (1) and (2) that the best correlation with protein and separated from Thyroid cancer was that the strongest correlation of the first compound with amino acidity was found to be strongly linked with the amino acid (GLY 863) was associated with the functional group (hydroxide) $\mathrm{H}$-donor And $\mathrm{H}$-acceptor of protein amino acids as shown in Figures ((1-8)) and the second amino acid is (SER 904 ) associated with the functional group 
(hydroxide) acceptor

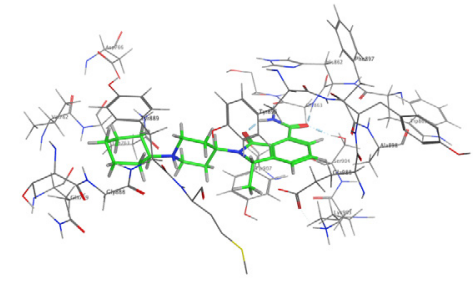

Figure 1 : ( Ligand with receptor ).
898

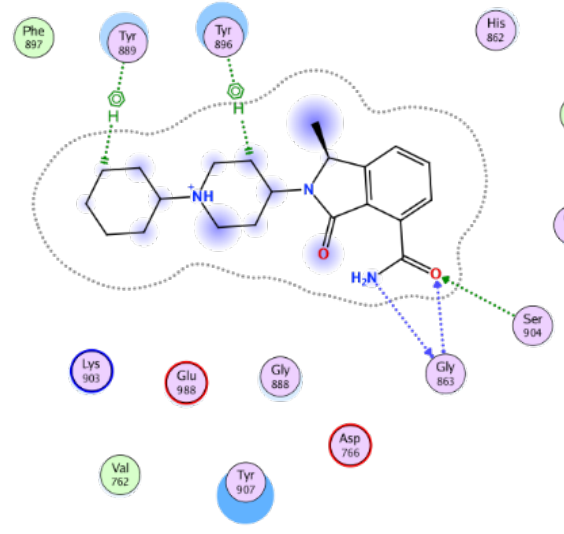

Figure 2: (Ligand with 618M enzyme)

Table. (1): Comparison of Ligand bond strength with BAI compound

Compound number $\quad S(\mathrm{Kcal} / \mathrm{mol})$

Ligand

Ligand

BAI

BAI

$$
\begin{aligned}
& -7.9142 \\
& -7.9142 \\
& -5.4426
\end{aligned}
$$

$-5.4426$
Amino acid interaction

function group interaction

SER 904

Amin

GLY 863

OG

GLY 863

Hydroxide

\begin{tabular}{|c|c|c|c|c|}
\hline Receptor & $E(\mathrm{Kcal} / \mathrm{mol})$ & Amino acid interaction & interaction & Distance \\
\hline 0 & -3.0 & GLY 863 & H-donor & 3.17 \\
\hline $\mathrm{N}$ & -3.9 & GLY 863 & H-acceptor & 3.07 \\
\hline OG & -1.3 & SER 904 & H-acceptor & 3.10 \\
\hline 6-ring & -1.2 & TYR & H-pi & 3.93 \\
\hline 6-ring & -0.6 & TYR & $\mathrm{H}-\mathrm{pi}$ & 3.83 \\
\hline
\end{tabular}

SER 904

Hydroxide 


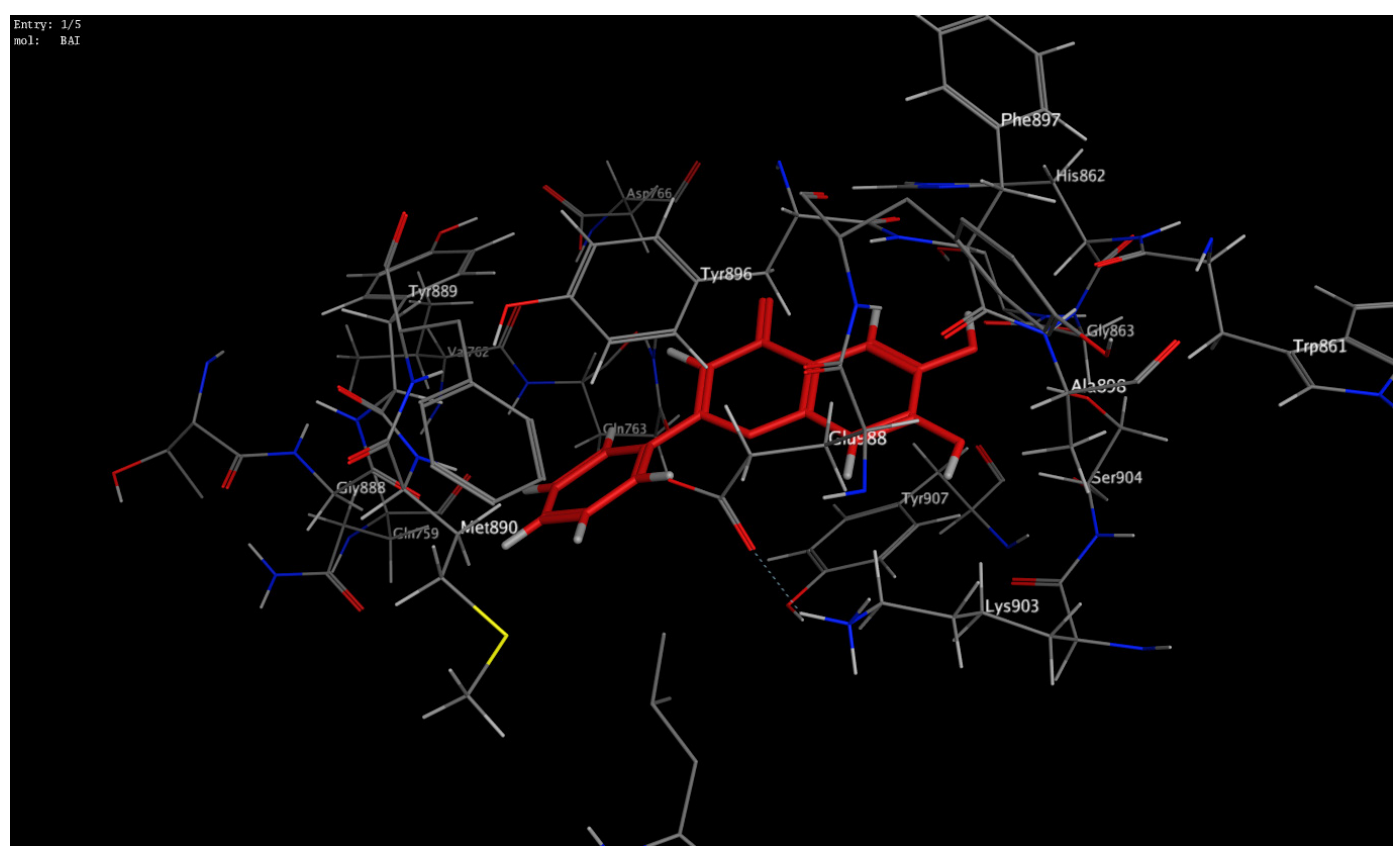

Figure 3: (compound configuration 1 with receptor).

\begin{tabular}{|c|c|c|c|c|}
\hline Receptor & $E(\mathrm{Kcal} / \mathrm{mol})$ & Amino acid interaction & interaction & Distance \\
\hline 0 & -4.4 & GLY 863 & H-donor & 2.90 \\
\hline $\mathrm{N}$ & -5.1 & GLY 863 & $\mathrm{H}$-acceptor & 2.87 \\
\hline OG & -2.7 & SER 904 & $\mathrm{H}$-acceptor & 2.72 \\
\hline
\end{tabular}

논군

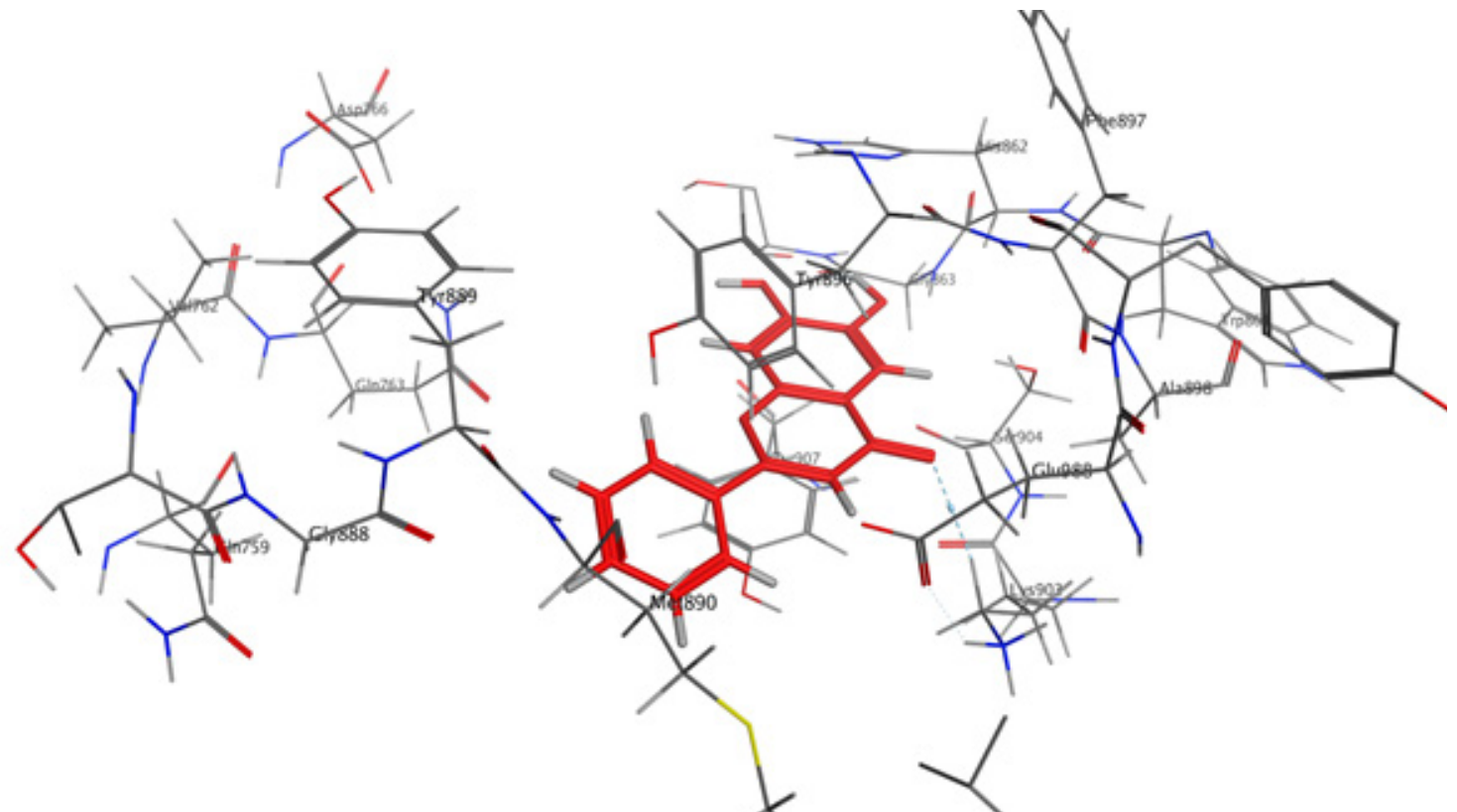

Figure 4: (compound configuration 1 with receptor). 


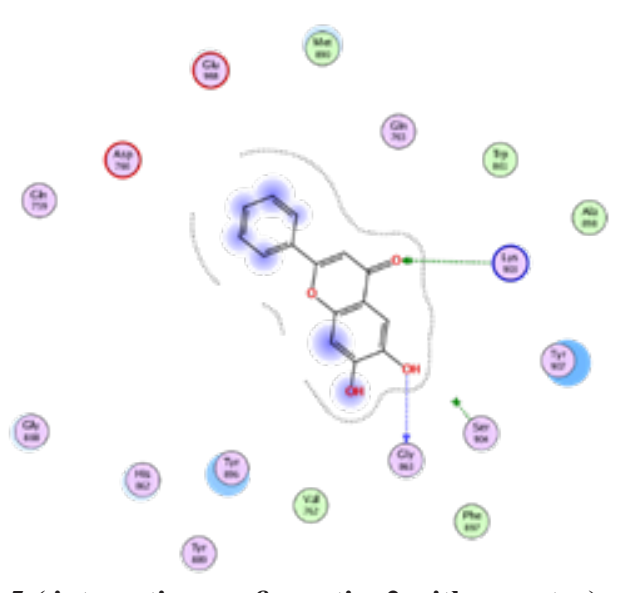

Figure 5:( interaction configuration2 with receptor)

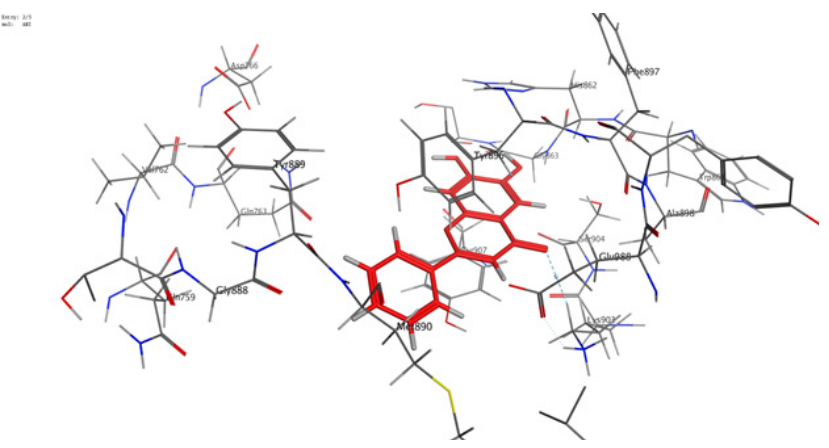

Figure 6: (compound configuration 3 with receptor).

(4)

(용

(18)

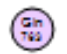

(720)

(4)
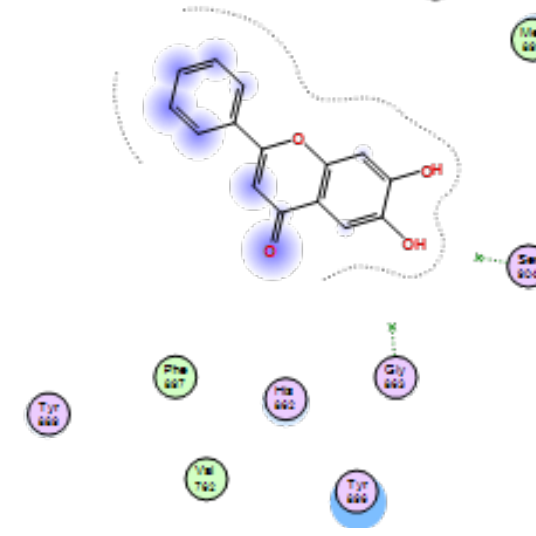

Figure 7 (interaction configuration 3 with receptor)

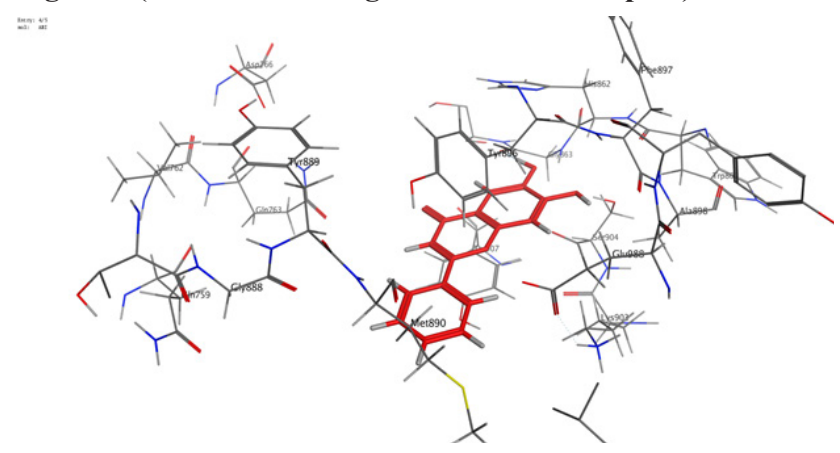

Figure 8: (compound configuration 4 with receptor). $=x$

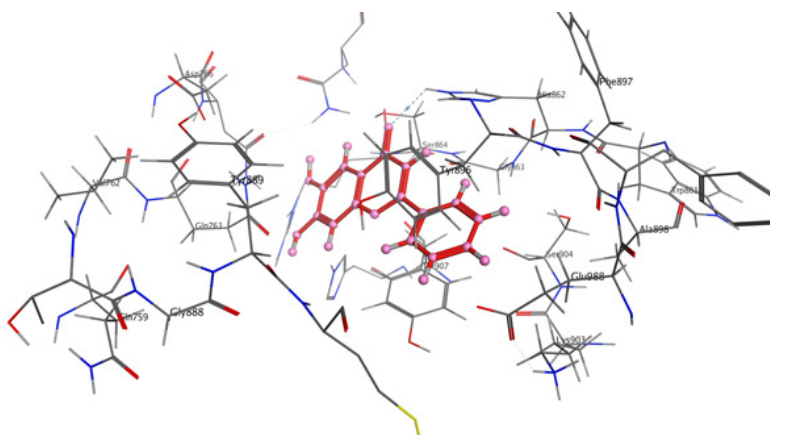

Figure 9 (compound and resepter)

\section{Conclusion}

We have computer-generated compound from the former researchers (SEUN HAN et. el) with Baicalein (6,7-dihydroxy-2-phenyl-4H-chromen-4-one) compound. Bendable docking of ligand to receptor molecules is an emerging method and is extensively used to reduce cost and time in drug innovation.

From the results, a process was showed to detect the strength of the link between the compound and the enzyme using the program (MOE), from the previous literature that showed efficacy as anti-fungal and some bacteria and the effect of these compound on thyroid cells cancer and inhibition of the causative enzyme (PARP)

Thus, this study showed that the compound (1) takes the best formula of is alignment more the association with the link with amino acids (GLY 836and SER 904) and gives the best consequences, thus clarifying the best inhibitor of the association with the enzyme.

Ethical Clearance: The Research Ethical Committee at scientific research by ethical approval of both environmental and health and higher education and scientific research ministries in Iraq

Conflict of Interest: The authors declare that they have no conflict of interest.

Funding: Self-funding

\section{References}

1. M. F. Mahomoodally, A. Gurib-Fakim, and A. H. Subratty, "Antimicrobial activities and phytochemical profiles of endemic medicinal plants of Mauritius," Pharmaceutical Biology, vol. 43, no. 3, pp. 237-242, 2005.

2. A. K. Pandey, "Anti-staphylococcal activity of a pantropical aggressive and obnoxious weed Parihenium 
histerophorus: an in vitro study," National Academy Science Letters, vol. 30, no. 11-12, pp. 383-386, 2007.

3. R. A. Dixon, P. M. Dey, and C. J. Lamb, "Phytoalexins: enzymology and molecular biology," Advances in Enzymology and Related Areas of Molecular Biology, vol. 55, pp. 1-136, 1983.

4. E. H. Kelly, R. T. Anthony, and J. B. Dennis, "Flavonoid antioxidants: chemistry, metabolism and structure-activity relationships," Journal of Nutritional Biochemistry, vol. 13, no. 10, pp. 572584, 2002.

5. S. Kumar, A. Mishra, and A. K. Pandey, "Antioxidant mediated protective effect of Parthenium hysterophorus against oxidative damage using in vitro models," BMC Complementary and Alternative Medicine, vol. 13, article 120, 2013.

6. ar and A. K. Pandey, "Phenolic content, reducing power and membrane protective activities of Solanum xanthocarpum root extracts," Vegetos, vol. 26, pp. 301-307, 2013

7. M. Leopoldini, N. Russo, S. Chiodo, and M. Toscano, "Iron chelation by the powerful antioxidant flavonoid quercetin," Journal of Agricultural and Food Chemistry, vol. 54, no. 17, pp. 6343-6351, 2006.

8. S. Kumar, A. Gupta, and A. K. Pandey, "Calotropis procera root extract has capability to combat free radical mediated damage," ISRN Pharmacology, vol. 2013, Article ID 691372, 8 pages, 2013.

9. N. C. Cook and S. Samman, "Review: flavonoidschemistry, metabolism, cardioprotective effects and dietary sources," Journal of Nutritional Biochemistry, vol. 7, no. 2, pp. 66-76, 1996.

10. C. A. Rice-Evans, N. J. Miller, P. G. Bolwell, P. M. Broamley, and J. B. Pridham, "The relative antioxidant activities of plant-derived polyphenolic flavonoids," Free Radical Research, vol. 22, no. 4, pp. 375-383, 1995.

11. G. Agati, E. Azzarello, S. Pollastri, and M. Tattini, "Flavonoids as antioxidants in plants: location and functional significance," Plant Science, vol. 196, pp.
67-76, 2012.

12. ng, F. Chen et al., "Advances in microbial heterologous production of flavonoids," African Journal of Microbiology Research, vol. 5, no. 18, pp. 2566-2574, 2011.

13. E. J. Middleton, "Effect of plant flavonoids on immune and inflammatory cell function," Advances in Experimental Medicine and Biology, vol. 439, pp. 175-182, 1998.

14. Amé J-C, Spenlehauer C, de Murcia G. The PARP superfamily. BioEssays. 2004;26(8):882-93.

15. D'Amours D, Desnoyers S, D'Silva I, Poirier GG. Poly(ADP-ribosyl)ation reactions in the regulation of nuclear functions. Biochem J. 1999;342(2):24968.

16. Amé JC, Rolli V, Schreiber V, Niedergang C, Apiou F, Decker P, Muller S, Höger T, Ménissier-de Murcia J, de Murcia G.. PARP-2, A Novel Mammalian DNA Damagedependent Poly(ADP-ribose) Polymerase. J Biol Chem. 1999;274(25):17860-8.

17. Lam AK. Pathology of Endocrine Tumors Update: World Health Organization New Classification 2017 - Other Thyroid Tumors. AJSP: Reviews \& Reports. 2017; 22: 209-16.

18. Bychkov A. World Health Organization (WHO) classification. http://www.pathologyoutlines.com/ topic/thyroidwho.html. Accessed September 11th, 2018.

19. Maia FFR, Zantut-Wittmann DE. Thyroid nodule management: Clinical, ultrasound and cytopathological parameters for predicting malignancy. Clinics. 2012; 67: 945-54.

20. Paricharttanakul NM, Saharat K, Chokchaichamnankit D, Punyarit P, Srisomsap C, Svasti J. Unveiling a novel biomarker panel for diagnosis and classification of well-differentiated thyroid carcinomas. Oncol Rep. 2016; 35: 2286-96.

21. Liu TR, Xiao ZW, Xu HN, Long Z, Wei FQ, Zhuang $\mathrm{SM}$, et al. Treatment and prognosis of anaplastic thyroid carcinoma: A clinical study of 50 cases. Plops One. 2016; 11: e0164840. 